\title{
Effects of Frequency and Duration of Interrupting Sitting on Cardiometabolic Risk Markers
}

\author{
Authors \\ Benjamin D. Maylor ${ }^{1}$, Julia K. Zakrzewski-Fruer ${ }^{1}$, David J. Stensel2, 3, Charlie J. Orton ${ }^{1}$, Daniel P. Bailey ${ }^{1}$
}

\section{Affiliations}

1 Institute for Sport and Physical Activity Research, School of Sport Science and Physical Activity, University of Bedfordshire, Bedford, United Kingdom of Great Britain and Northern Ireland

2 National Centre for Sport and Exercise Medicine, School of Sport, Exercise and Health Sciences, Loughborough University, Loughborough, United Kingdom of Great Britain and Northern Ireland

3 University Hospitals of Leicester NHS Trust, Leicester, United Kingdom of Great Britain and Northern Ireland

\section{Key words}

physical activity, sedentary behaviour, glycaemia, lipids, activity breaks

accepted 23.07.2019

\section{Bibliography}

DOI https://doi.org/10.1055/a-0997-6650

Published online: 9.9.2019

Int J Sports Med 2019; 40: 818-824

(c) Georg Thieme Verlag KG Stuttgart · New York

ISSN 0172-4622

\section{Correspondence}

Dr. Daniel Bailey

School of Sport Science and Physical Activity

University of Bedfordshire

Polhill Avenue

MK41 9EA Bedford

United Kingdom

of Great Britain and Northern Ireland

Tel.: + 44(0)1234 793237

daniel.bailey@beds.ac.uk

\section{ABSTRACT}

Interrupting prolonged sitting with short multiple bouts of moderate-intensity physical activity (PA) can improve postprandial cardiometabolic risk markers. This study examined the effect of high and low frequency PA bouts (matched for total PA duration and energy expenditure) on postprandial cardiometabolic responses when compared with prolonged sitting. In this three-condition randomised crossover trial, 14 sedentary, inactive females ( $33.8 \pm 13.4$ years, BMI $\left.27.1 \pm 6.3 \mathrm{~kg} / \mathrm{m}^{2}\right)$ completed 3, 7.5 h conditions: 1) prolonged sitting (SIT), 2) high-frequency PA breaks (HIGH-FREQ) consisting of $15 \times 2$ min bouts of moderate-intensity treadmill PA every $30 \mathrm{~min}$, and 3) low-frequency PA breaks (LOW-FREQ) consisting of $3 \times 10 \mathrm{~min}$ bouts of moderate-intensity treadmill PA every $180 \mathrm{~min}$. The PA bouts were performed at $65 \%$ of peak oxygen uptake. Net incremental area under the curve (iAUC) for each $7.5 \mathrm{~h}$ condition was calculated for glucose, insulin and triacylglycerol (TAG) concentrations. Insulin iAUC was significantly $(p<0.026)$ lower during HIGH-FREQ (mean [95\%Cl]; $82.86[55.02,110.70] \mu \mathrm{U} /$ $\mathrm{mL} \cdot 7.5 \mathrm{~h})$ than LOW-FREQ $(116.61[88.50,144.73] \mu \mathrm{U} /$ $\mathrm{mL} \cdot 7.5 \mathrm{~h})$ and SIT $(119.98[92.42,147.53] \mu \mathrm{U} / \mathrm{mL} \cdot 7.5 \mathrm{~h})$. Glucose and TAG iAUC did not differ between conditions. Engaging in higher-frequency PA breaks may be effective in attenuating postprandial insulin responses compared with lower-frequency PA breaks and prolonged sitting.

\section{Introduction}

Increased postprandial levels of glucose, insulin, and triacylglycerol (TAG) promote oxidative stress, inflammation, and endothelial dysfunction that can increase the risk of cardiometabolic disease $[1,2]$. Acute responses and chronic adaptations to engaging in physical activity (PA) can attenuate elevations in these cardiometabolic risk markers [3-5]. Accordingly, current UK PA guidelines recommend that adults engage in $\geq 150 \mathrm{~min} /$ week of moderate- to-vigorous physical activity (MVPA) accumulated in bouts of $\geq 10 \mathrm{~min}$ to benefit their health [6].

Several studies have reported that accumulating moderate-intensity PA in regular short bouts of $\leq 3 \mathrm{~min}$ in duration is effective for attenuating postprandial glucose, insulin and TAG responses over a single day [7-10]. Furthermore, the cardiometabolic benefits of short frequent bouts of PA may be equally or more effective than a single continuous bout of PA of the same intensity and vol- 
ume (typically $30 \mathrm{~min}$ in duration) [9-11]. This may be because interrupting muscular inactivity that occurs during prolonged sitting suppresses postprandial glucose, insulin, and TAG levels via different mechanistic pathways than continuous PA [12]. However, the effects of regular short bouts of PA compared with less frequent bouts of $\geq 10$ min that are recommended in government guidelines [6] are unknown.

The aim of this study was to compare the postprandial cardiometabolic effects of frequent short bouts of PA used to interrupt sitting time to an equal volume of PA accumulated in less frequent 10 min bouts in sedentary females.

\section{Materials and Methods}

This randomised crossover study was approved by the University of Bedfordshire Institute for Sport and Physical Activity Research Ethics Committee and adhered to published ethical standards [13]. All testing took place at the University of Bedfordshire Sport and Exercise Science Laboratories. After a preliminary visit, participants completed 3 experimental conditions in an incomplete counterbalanced order pre-determined using the Latin square method. Participants were blinded to the first two experimental conditions that they were taking part in until they arrived in the morning to complete those respective conditions.

\section{Participants}

Fourteen sedentary (defined as self-reported sedentary time $\geq 7 \mathrm{~h}$ / day because volumes above this threshold are associated with increased cardiometabolic disease risk [14]) and inactive (self-reported MVPA < $150 \mathrm{~min} /$ week or < 75 min vigorous PA [6]) females aged 20-55 years provided informed consent to participate in the study. Participants were recruited between November 2015 and August 2016. Exclusion criteria included working in a non-sedentary occupation, any known blood borne disease, pregnancy, diabetes, taking glucose-lowering and/or lipid-lowering medication, known PA contraindications, major illness/injury, or allergies to the test meals being provided.

\section{Preliminary visit}

Participants attended a preliminary testing session to have stature (Holtain Ltd., Crymych, Wales), body mass, and body composition (Tanita BC-418 Segmental Body Composition Analyzer, Tanita Corp., Tokyo, Japan) measured. To ascertain a treadmill speed for the experimental conditions, participants completed a $4 \times 4$ min submaximal and a maximal oxygen uptake test on a motorised treadmill (Woodway PPS55Med-I, GmbH, Germany). Breath-bybreath expired air samples were collected throughout both tests using an online gas analysis system (Cortex Metalyzer 3B, $\mathrm{GmbH}$, Germany). Participants started both tests at a walking speed that they felt they could comfortably maintain for $30 \mathrm{~min}$. The submaximal test speed was increased by $1.5 \mathrm{~km} / \mathrm{h}$ per stage. After a $\sim 30$ min supervised rest, the maximal oxygen uptake test was completed, where the speed was increased by $1 \mathrm{~km} / \mathrm{h}$ every three min until volitional exhaustion. Maximal oxygen uptake $\left(\dot{\mathrm{V}}_{2 \max }\right)$ was taken as the highest $\dot{\mathrm{V}} \mathrm{O}_{2}$ value over a 10 s period and was accepted as valid if a plateau in $\mathrm{VO}_{2}\left(\leq 2.1 \mathrm{~mL} \cdot \mathrm{kg}^{-1} \cdot \mathrm{min}^{-1}\right)$ occurred despite increasing workload [15]. Peak oxygen uptake was taken if a plateau was not attained but $\geq 2$ of the following end-point criteria were satisfied: 1 ) heart rate within $10 \mathrm{bpm}$ of age predicted maximum, 2) respiratory exchange ratio $>1.1$, and 3 ) Rating of Perceived Exertion (RPE) $\geq 18$ [16]. The relationship between treadmill speed and $\% \dot{\mathrm{V}} \mathrm{O}_{2 \text { peak }}$ was used to estimate the treadmill speed that elicited $65 \% \dot{\mathrm{V}} \mathrm{O}_{2 \text { peak }}$ for use during the experimental conditions.

\section{Experimental protocol}

Due to hormonal alterations in glucose metabolism during the female menstrual cycle [17], experimental conditions were completed during the follicular phase only (days $1-10$ ). There was a minimum of a 7-day washout period between each condition to minimise carryover effects. Prior to each experimental condition, participants refrained from exercise, alcohol, and caffeine for $48 \mathrm{~h}$. Participants recorded the weight and timings of all food and liquid intake in a food diary for $24 \mathrm{~h}$ before the first experimental condition and were asked to replicate the quantity and timings of consumption prior to each subsequent condition [7]. Participants arrived at the laboratories at $\sim 08: 30$ in a fasted state following a vehicular commute. Fasting blood samples were collected following insertion of a cannula into an antecubital vein. Following this, participants undertook one of three, $7.5 \mathrm{~h}$ experimental conditions (see $>$ Fig. 1):

1) SIT: Uninterrupted sitting at a desk.

2) HIGH-FREQ: Sitting interrupted with frequent, 2-min moderate-intensity treadmill PA breaks every $30 \mathrm{~min}$.

3) LOW-FREQ: Sitting interrupted with less frequent, 10-min moderate-intensity treadmill PA breaks at $0 \mathrm{~min}, 170 \mathrm{~min}$, and $350 \mathrm{~min}$.

To match the PA conditions for PA intensity and energy expenditure, all PA was performed at a treadmill speed that corresponded to $65 \% \dot{\mathrm{V}} \mathrm{O}_{\text {peak }}$ and the total duration of PA was $30 \mathrm{~min}$ in both conditions. The moderate-intensity PA was a walking pace for some participants and a jogging pace for others. RPE was obtained during the last $30 \mathrm{~s}$ of each treadmill bout using the Borg scale [18]. During experimental conditions, participants were permitted to work on a laptop computer, read, or talk during sitting periods and were supervised by a researcher to ensure adherence to the protocols. Participants were permitted to void when necessary with the toilets being located $\sim 30 \mathrm{~m}$ from the laboratory.

Two standardised test meals were provided during each condition: one at $15 \mathrm{~min}$ and one at $180 \mathrm{~min}$. These were individualised to provide 15 and $25 \%$, respectively, of estimated daily energy requirements for each participant. Energy requirements were estimated using the Mifflin equation with a PA factor of 1.4 applied to represent a sedentary day [19]. The first meal provided $58 \%$ carbohydrate $(43.1 \pm 8.1 \mathrm{~g}), 28 \%$ fat $(9.4 \pm 1.8 \mathrm{~g})$ and $14 \%$ protein $(10.7 \pm 2.0 \mathrm{~g})$ with a mean energy intake of $1274.4 \pm 240.2 \mathrm{~kJ}$. The meal consisted of cornflakes and whole milk (glycaemic index: 80; based on the individual food items' glycaemic index values reported in international tables [20] and taking into account the weighted contribution of carbohydrate from each food item [21]). The second meal provided $46 \%$ carbohydrate $(57.6 \pm 10.0 \mathrm{~g}), 40 \%$ fat $(22.3 \pm 3.9 \mathrm{~g})$ and $14 \%$ protein $(17.8 \pm 3.1 \mathrm{~g})$ with a mean energy in- 


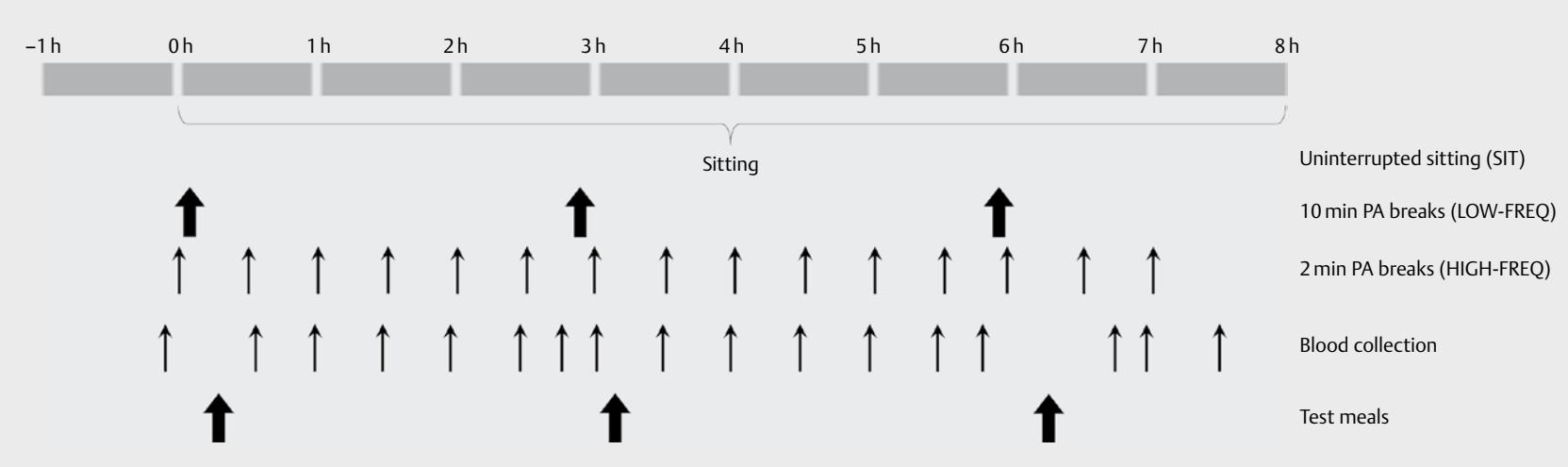

- Fig 1 Schematic of experimental condition protocols. PA, physical activity; HIGH-FREQ, sitting interrupted with 2 min PA breaks every 30 min; LOW-FREQ, sitting interrupted with 10 min PA breaks every 180 min.

take of $2123.4 \pm 220.9 \mathrm{~kJ}$. This meal consisted of white bread, roast chicken, margarine, crisps and chocolate (glycaemic index: 58 ). At $6 \mathrm{~h}$, participants were given $30 \mathrm{~min}$ ad libitum access to a cold food buffet. The items available were white bread, wholemeal bread, margarine, mayonnaise, cheese, ham, crisps, chocolate bars, cereal bars, cookies, apples, oranges, bananas, milk and orange juice. All items were provided in standardised quantities and the total volume provided was expected to exceed the amount that would be consumed. Participants were provided with water ad libitum during the first experimental condition; this same volume was provided spread across the day in the subsequent experimental conditions.

Blood samples were collected into two $4.9 \mathrm{~mL}$ EDTA-containing vacuettes (Vacuette, Greiner Bio-One, Austria) at the time points shown in $>$ Fig. 1. From 1 vacuette, $50 \mu$ of whole blood was immediately pipetted into a microvette (Microvette CB300 EDTA, Sarstedt Ltd, Leicester, UK) from which glucose concentrations were measured at $0,35,60,90,120,150,165,180,210,240,270$, $300,330,345,405,420$ and 450 min using the YSI 2300 STAT plus glucose and lactate analyzer (YSI Inc., Yellow Springs, OH, USA). The remaining blood was centrifuged (Heraeus, Heraeus Multifuge $\mathrm{X} 3 \mathrm{R}$, Thermo Scientific) at $1500 \times \mathrm{g}$ for $10 \mathrm{~min}$ at $4^{\circ} \mathrm{C}$. The plasma supernatant was stored at $-80^{\circ} \mathrm{C}$ for later batch analysis of insulin and TAG at $0,35,60,120,165,180,210,240,300,345,405$ and $450 \mathrm{~min}$. Plasma insulin concentrations were measured using a commercially available enzyme-linked immunosorbent assay kit (Mercodia, Uppsala, Sweden). Plasma TAG concentrations were determined via spectrophotometry using the lipase hydrolysis method (GOP-PAP; Randox Laboratories Ltd, Crumlin, UK).

\section{Calculations and statistical analysis}

Postprandial glucose, insulin and TAG outcomes were calculated for each $7.5 \mathrm{~h}$ experimental condition using the trapezoidal method. Total area under the curve (TAUC) was calculated; the area under the baseline value was subtracted to calculate net incremental area under the curve (iAUC). Statistical analyses were completed using SPSS version 22.0 (SPSS Inc., Armonk, N.Y., USA). Normality was assessed using standard graphical procedures [22]. Insulin
iAUC was non-normally distributed and was log transformed prior to analysis. The data were back-transformed to natural units to provide meaningful interpretation of the results. Linear mixed models with fixed ('condition') and random ('participant') effects were fitted using the correlation structure yielding the lowest Hurvich and Tsai's information criterion (AICC) [23]. All models were adjusted for potential covariates (age, body fat $\%$ and baseline outcome values). Post hoc analyses were adjusted using the Sidak correction for multiple comparisons. Cohens' d effect sizes were calculated to describe the magnitude of significant differences between conditions with $0.2,0.5$ and 0.8 indicating a small, medium and large effect, respectively [24]. Data are presented as mean (95\% confidence interval $[\mathrm{Cl}])$ unless stated otherwise. Significance was accepted as $p \leq 0.05$.

\section{Results}

14 participants were recruited who each completed the full trial. The characteristics of the participants are shown in $>$ Table 1. Nine of the participants attained a $\dot{\mathrm{VO}}_{2}$ plateau and the remaining 5 participants met the secondary criteria for $\dot{\mathrm{V}}_{2 \text { peak }}$.

Baseline cardiometabolic risk marker concentrations did not differ significantly between conditions ( $\triangleright$ Table 2 ). The mean RPE was significantly higher during the LOW-FREQ PA bouts $(11.7 \pm 1.7)$ than the HIGH-FREQ PA bouts $(10.4 \pm 1.4 ; \mathrm{p}=0.001)$. Total energy and macronutrient intake during the buffet meal was similar between conditions ( $\triangleright$ Table 2 ). There was a significant main effect of condition for insulin iAUC with concentrations being significantly lower by $31 \%$ and $29 \%$ in HIGH-FREQ compared with SIT ( $p=0.026$; $d=1.34)$ and LOW-FREQ ( $p=0.017 ; d=1.21)$, respectively. The effect sizes for these differences were large. Insulin TAUC was also significantly lower in HIGH-FREQ than SIT ( $p=0.020 ; d=0.56)$ and LOW-FREQ ( $p=0.050 ; d=0.52)$, with medium effect sizes. There were no significant main effects of condition for glucose or TAG outcomes. Cardiometabolic responses over time for each condition are shown in $\mathbf{F i g .} \mathbf{2}$ for descriptive purposes. 


\section{Discussion}

The main finding of this study was that postprandial insulin concentrations in sedentary, inactive females were attenuated in response to 2-min, frequent moderate-intensity PA breaks, but were not suppressed by engaging in the same duration of PA accumulated in less frequent, 10-min breaks when compared with uninterrupted sitting. Previous research examining the effects of PA breaks on postprandial insulin have yielded mixed findings. There are several acute experimental trials reporting that PA breaks every 20-30 min for durations between $1 \mathrm{~min} 40 \mathrm{~s}$ and 5 min suppressed postprandial insulin by $21-26 \%$ in healthy and dysglycaemic adults [10,25-29], whilst other trials incorporating similar designs have reported no suppression of insulin $[7,8]$. Although study designs are similar, it is possible that the shorter observation periods and provision of only one meal during the experimental conditions could have reduced the potential to detect differences in insulin in some studies [7, 8, 25]. Indeed, the study by Henson et al. [27] provided two meals across an experimental period the same duration as the present study $(7.5 \mathrm{~h}$ ) and they observed a suppression in postprandial insulin. Alternatively, previous studies reporting no differences $[7,8]$ were not powered to detect changes in insulin and the sample sizes may thus have been insufficient. However, a

- Table 1 Participant characteristics $(n=14)$.

\begin{tabular}{|l|c|}
\hline Characteristic & Mean \pm SD \\
\hline Age (years) & $33.8 \pm 13.4$ \\
\hline Height $(\mathrm{cm})$ & $168.1 \pm 5.3$ \\
\hline Weight $(\mathrm{kg})$ & $76.4 \pm 17.4$ \\
\hline Body mass index $\left(\mathrm{kg} / \mathrm{m}^{2}\right)$ & $27.1 \pm 6.3$ \\
\hline Body fat $(\%)$ & $32.9 \pm 10.9$ \\
\hline Peak oxygen uptake $\left(\mathrm{mL} \cdot \mathrm{kg}^{-1} \cdot \mathrm{min}^{-1}\right)$ & $34.5 \pm 6.6$ \\
\hline
\end{tabular}

similar number of participants was used in the present study where significant differences were detected. It is possible that the participants in previous studies $[7,8]$ may have been at the healthy end of the metabolic risk spectrum [30] and able to dispose of more glucose under the presence of similar insulin concentrations in response to PA breaks compared with participants in the current study and the studies by Henson et al. [27] and Chrismas et al. [29]. Further adequately powered studies are required to establish the effects of PA breaks across the metabolic risk spectrum.

This study is the first, to our knowledge, to directly examine the acute effects of accumulating volume and intensity-matched PA in different frequencies on postprandial metabolism. Despite the current UK PA guidelines recommending that MVPA is accumulated in bouts of $\geq 10$ min to benefit health [6], we observed that engaging in three, 10-min PA bouts separated by $\sim 3 \mathrm{~h}$ did not suppress postprandial insulin compared to uninterrupted sitting. Conversely, engaging in 2-min PA breaks every 30 min suppressed insulin by $\sim 30 \%$ compared with uninterrupted sitting and engaging in 10min PA bouts spread across the day. Previous research has shown that insulin was suppressed by $18 \%$ in response to 1 min 40 s walking breaks every 30 min compared with a single continuous intensity-matched 30 min walking bout [10]. Conversely, another study observed no difference in postprandial insulin between a single continuous 60-min bout of moderate-intensity PA compared with 5-min intensity-matched PA breaks spread over $10 \mathrm{~h}$ [31], possibly because the frequency of PA breaks was insufficient. The more frequent PA breaks in the present study and the study by Peddie et al. [10] may have upregulated or maintained insulin sensitivity related pathways, whereas 10-min PA bouts performed approximately every $3 \mathrm{~h}$ were not sufficient. This suggests that interrupting sitting with shorter, more frequent PA breaks may be more beneficial than engaging in longer, less frequent PA breaks. Additionally, participants reported lower levels of perceived exertion whilst engaging

- Table 2 Biochemical and nutritional intake values for each condition.

\begin{tabular}{|l|c|c|c|}
\hline Variable & Prolonged sitting & HIGH-FREQ & LOW-FREQ \\
of condition
\end{tabular}



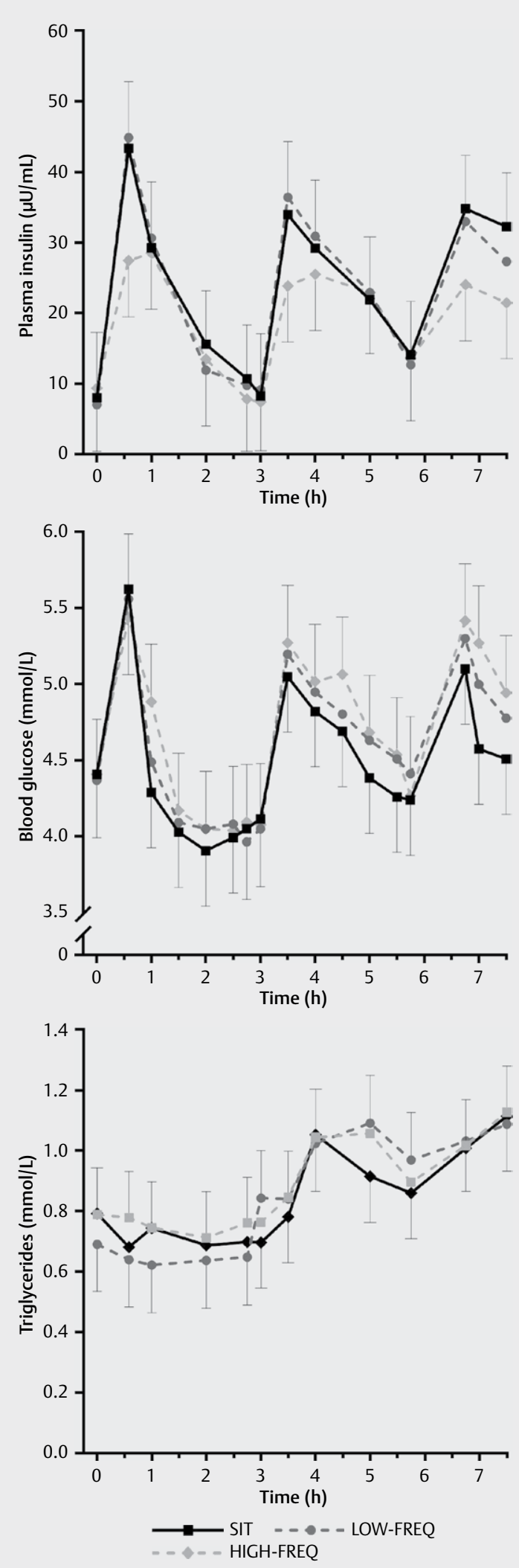

Fig. 2 Changes in insulin, glucose, and triacylglycerol concentrations during prolonged sitting (SIT), sitting interrupted with $2 \mathrm{~min} P A$ breaks every $30 \mathrm{~min}$ (HIGH-FREQ), and sitting interrupted with $10 \mathrm{~min}$ PA breaks every 180 min (LOW-FREQ). Data are mean and $95 \%$ confidence intervals. Some error bars have been omitted for clarity. in the more frequent breaks. This type of PA regime may thus be more achievable for inactive and sedentary adults in addition to offering greater cardiometabolic benefits.

Despite several reports of attenuated postprandial glucose concentrations in response to short, frequent moderate-intensity PA breaks in healthy adults [7, 8, 32], adults who are overweight/obese $[10,33,34]$ and individuals with type 2 diabetes $[35,36]$, postprandial glucose was unaffected by the PA breaks in the present study. The sample in the present study could be considered metabolically healthy due to their normal fasting glucose levels. It has been suggested that individuals who are metabolically healthy may reduce the amount of insulin required to maintain normal glucose homeostasis in response to interrupting sitting [30]. This would thus explain the lack of change in postprandial glucose observed here. Additionally, the lack of change may have been due to the relatively low elevation in blood glucose after the test meals, which could have limited the potential of the PA breaks to attenuate glucose. We chose to provide participants with a mixed meal to reflect habitual dietary intakes. Although the predicted glycaemic index of the breakfast was high, the lunch had a moderate glycaemic index and potentially did not stimulate a large enough glucose response that could have been attenuated by PA breaks. Suppressions in postprandial glucose in response to PA breaks may therefore only be observed after consumption of higher glycaemic index meals, as postulated previously [8].

The evidence that regular PA breaks can attenuate postprandial TAG is mixed, with some studies observing beneficial changes $[11,37,38]$ and others not $[10,39,40]$. Due to the heterogenous nature of the PA breaks (intensity, frequency and duration) and sample characteristics across studies, the reasons for these differences are not clear [4]. That said, lipoprotein lipase (LPL) activity typically peaks > 8-22 h after moderate-intensity PA [41] and research that measured the postprandial TAG response to a high-fat test meal the day after engaging in regular PA breaks has typically reported beneficial responses [9,42-44]. Thus, the lack of timelag between the PA and postprandial measurements and the provision of test meals, where $28-40 \%$ of the energy was derived from fat, may explain our null findings. It is also possible that the moderate-intensity PA in the current study was not of a sufficient intensity to elevate LPL activity during the $7.5 \mathrm{~h}$ experimental period [38]. As physical activity energy expenditure directly affects postprandial lipaemic responses more strongly than PA intensity or duration [45], the 30 min PA completed during the PA conditions may have also been insufficient. Nonetheless, this volume of walking has been effective in previous studies [37] when the postprandial challenge took place the following day, which may suggest PA timing is key.

A strength of the present study is that it was conducted in females who have been less represented in PA and postprandial research. However, this also poses a limitation as it is not known whether the findings would be generalisable to males. A greater attenuation in postprandial glucose responses to light-intensity PA breaks has been previously seen in females versus males [35]. However, another study found that sex did not affect acute responses to interrupting sitting [46]. Further research investigating potential sex differences is thus required. The experimental protocols in this study were completed in a controlled laboratory environment. 
Future research should investigate the efficacy of engaging in frequent PA breaks in free-living settings, such as in the workplace and at home.

In conclusion, this study observed a significant attenuation in postprandial insulin concentrations in response to interrupting sitting with frequent 2-min moderate-intensity PA breaks compared with less frequent 10-min PA bouts of the same intensity and total duration and compared with uninterrupted sitting. Frequent PA breaks may, therefore, be a beneficial strategy to reduce cardiometabolic disease risk in sedentary females.

\section{Acknowledgements}

David Stensel acknowledges support from the NIHR Leicester Biomedical Research Centre. The views expressed are those of the author(s) and not necessarily those of the NHS, the NIHR or the Department of Health and Social Care.

\section{Conflict of Interest}

The authors declare that they have no conflict of interest.

\section{References}

[1] Loader J, Montero D, Lorenzen C, Watts R, Meziat C, Reboul C, Stewart S, Walther $\mathrm{G}$. Acute hyperglycemia impairs vascular function in healthy and cardiometabolic diseased subjects: systematic review and meta-analysis. Arterioscler Thromb Vasc Biol 2015; 35: 2060-2072

[2] O'Keefe JH, Bell DS. Postprandial hyperglycemia/hyperlipidemia (postprandial dysmetabolism) is a cardiovascular risk factor. Am J Cardiol 2007; 100: 899-904

[3] Alves AJ, Viana JL, Cavalcante SL, Oliveira NL, Duarte JA, Mota J, Oliveira J, Ribeiro F. Physical activity in primary and secondary prevention of cardiovascular disease: Overview updated. World J Cardiol 2016; 8: 575-583

[4] Benatti FB, Ried-Larsen M. The effects of breaking up prolonged sitting time: A review of experimental studies. Med Sci Sports Exerc 2015; 47: 2053-2061

[5] Myers ], McAuley P, Lavie C], Despres JP, Arena R, Kokkinos P. Physical activity and cardiorespiratory fitness as major markers of cardiovascular risk: Their independent and interwoven importance to health status. Prog Cardiovasc Dis 2015; 57: 306-314

[6] Department of Health. UK Physical Activity Guidelines. 2011; In internet: https://www.gov.uk/government/publications/uk-physicalactivity-guidelines; (19 January 2019)

[7] Bailey DP, Broom DR, Chrismas BC, Taylor L, Flynn E, Hough J. Breaking up prolonged sitting time with walking does not affect appetite or gut hormone concentrations but does induce an energy deficit and suppresses postprandial glycaemia in sedentary adults. Appl Physiol Nutr Metab 2016; 41: 324-331

[8] Bailey DP, Maylor BD, Orton CJ, Zakrzewski-Fruer JK. Effects of breaking up prolonged sitting following low and high glycaemic index breakfast consumption on glucose and insulin concentrations. Eur ] Appl Physiol 2017; 117: 1299-1307

[9] Miyashita M. Effects of continuous versus accumulated activity patterns on postprandial triacylglycerol concentrations in obese men. Int J Obes (Lond) 2008; 32: 1271-1278
[10] Peddie MC, Bone JL, Rehrer N], Skeaff CM, Gray AR, Perry TL. Breaking prolonged sitting reduces postprandial glycemia in healthy, normalweight adults: A randomized crossover trial. Am J Clin Nutr 2013; 98: 358-366

[11] Miyashita M, Edamoto K, Kidokoro T, Yanaoka T, Kashiwabara K, Takahashi M, Burns S. Interrupting sitting time with regular walks attenuates postprandial triglycerides. Int J Sports Med 2016; 37: 97-103

[12] Hamilton M, Healy G, Dunstan D, Zderic T, Owen N. Too little exercise and too much sitting: Inactivity physiology and the need for new recommendations on sedentary behavior. Curr Cardiovasc Risk Rep 2008; 2: 292-298

[13] Harriss D], Macsween A, Atkinson G. Standards for ethics in sport and exercise science research: 2018 update. Int J Sports Med 2017; 38: $1126-1131$

[14] Matthews CE, George SM, Moore SC, Bowles HR, Blair A, Park Y, Troiano RP, Hollenbeck A, Schatzkin A. Amount of time spent in sedentary behaviors and cause-specific mortality in US adults. Am J Clin Nutr 2012; 95: 437-445

[15] Taylor HL, Buskirk E, Henschel A. Maximal oxygen intake as an objective measure of cardio-respiratory performance. J Appl Physiol 1955; 8: 73-80

[16] Mier CM, Alexander RP, Mageean AL. Achievement of $\mathrm{VO}_{2}$ max criteria during a continuous graded exercise test and a verification stage performed by college athletes. J Strength Cond Res 2012; 26: 2648-2654

[17] Schisterman EF, Mumford SL, Sjaarda LA. Failure to consider the menstrual cycle phase may cause misinterpretation of clinical and research findings of cardiometabolic biomarkers in premenopausal women. Epidemiol Rev 2014; 36: 71-82

[18] Borg GA. Psychophysical bases of perceived exertion. Med Sci Sports Exerc 1982; 14: 377-381

[19] Mifflin MD, St Jeor ST, Hill LA, Scott B], Daugherty SA, Koh YO. A new predictive equation for resting energy expenditure in healthy individuals. Am J Clin Nutr 1990; 51: 241-247

[20] Atkinson FS, Foster-Powell K, Brand-Miller JC. International tables of glycemic index and glycemic load values: 2008. Diabetes Care 2008; 31: 2281-2283

[21] Wolever TMS, Jenkins DJA. The use of the glycemic index in predicting the blood-glucose response to mixed meals. Am J Clin Nutr 1986; 43: 167-172

[22] Grafen G, Hails R. Modern Statistics for the Life Sciences. $1^{\text {st }}$ ed. New York, USA: Oxford University Press; 2002

[23] Hurvich CM, Tsai CL. Regression and time-series model selection in small samples. Biometrika 1989; 76: 297-307

[24] Cohen J. Statistical Power Analysis for the Behavioral Sciences. Hillsdale, N.J: L. Erlbaum Associates; 1988

[25] Dunstan DW, Kingwell BA, Larsen R, Healy GN, Cerin E, Hamilton MT, Shaw JE, Bertovic DA, Zimmet PZ, Salmon J, Owen N. Breaking up prolonged sitting reduces postprandial glucose and insulin responses. Diabetes Care 2012; 35: 976-983

[26] Pulsford RM, Blackwell J, Hillsdon M, Kos K. Intermittent walking, but not standing, improves postprandial insulin and glucose relative to sustained sitting: A randomised cross-over study in inactive middle-aged men. J Sci Med Sport 2017; 20: 278-283

[27] Henson J, Davies M], Bodicoat DH, Edwardson CL, Gill JM, Stensel DJ, Tolfrey K, Dunstan DW, Khunti K, Yates T. Breaking up prolonged sitting with standing or walking attenuates the postprandial metabolic response in postmenopausal women: A randomized acute study. Diabetes Care 2016; 39: 130-138 
[28] Homer AR, Fenemor SP, Perry TL, Rehrer N], Cameron CM, Skeaff CM, Peddie MC. Regular activity breaks combined with physical activity improve postprandial plasma triglyceride, nonesterified fatty acid, and insulin responses in healthy, normal weight adults: A randomized crossover trial. J Clin Lipidol 2017; 11: 1268-1279.e1261

[29] Chrismas BCR, Taylor L, Cherif A, Sayegh S, Rizk N, El-Gamal A, Allenjawi SH, Bailey DP. Postprandial insulin and triglyceride concentrations are suppressed in response to breaking up prolonged sitting in qatari females. Front Physiol 2019; 10: 706

[30] Homer AR, Owen N, Dunstan DW. Too much sitting and dysglycemia: Mechanistic links and implications for obesity. Current Opinion in Endocrine and Metabolic Research 2019; 4: 42-49

[31] Holmstrup M, Fairchild T, Keslacy S, Weinstock R, Kanaley J. Multiple short bouts of exercise over 12-h period reduce glucose excursions more than an energy-matched single bout of exercise. Metabolism 2014; 63: 510-519

[32] Thorsen IK, Johansen MY, Pilmark NS, Jespersen NZ, Brinklov CF, Benatti FB, Dunstan DW, Karstoft K, Pedersen BK, Ried-Larsen M. The effect of frequency of activity interruptions in prolonged sitting on postprandial glucose metabolism: A randomized crossover trial. Metabolism 2019; 96: 1-7

[33] McCarthy M, Edwardson CL, Davies M], Henson J, Rowlands A, King JA, Bodicoat DH, Khunti K, Yates T. Breaking up sedentary time with seated upper body activity can regulate metabolic health in obese high-risk adults: A randomized crossover trial. Diabetes Obes Metab 2017; 19: 1732-1739

[34] Climie RE, Grace MS, Larsen RL, Dempsey PC, Oberoi J, Cohen ND, Owen N, Kingwell BA, Dunstan DW. Regular brief interruptions to sitting after a high-energy evening meal attenuate glycemic excursions in overweight/obese adults. Nutr Metab Cardiovasc Dis 2018; 28: 909-916

[35] Dempsey PC, Larsen RN, Sethi P, Sacre JW, Straznicky NE, Cohen ND, Cerin E, Lambert GW, Owen N, Kingwell BA, Dunstan DW. Benefits for type 2 diabetes of interrupting prolonged sitting with brief bouts of light walking or simple resistance activities. Diabetes Care 2016; 39: 964-972

[36] Dempsey PC, Larsen RN, Winkler EAH, Owen N, Kingwell BA, Dunstan DW. Prolonged uninterrupted sitting elevates postprandial hyperglycaemia proportional to degree of insulin resistance. Diabetes Obes Metab 2018; 20: 1526-1530
[37] Miyashita M, Burns SF, Stensel D]. Accumulating short bouts of brisk walking reduces postprandial plasma triacylglycerol concentrations and resting blood pressure in healthy young men. Am J Clin Nutr 2008; 88: $1225-1231$

[38] Maylor BD, Zakrzewski-Fruer JK, Orton C], Bailey DP. Beneficial postprandial lipaemic effects of interrupting sedentary time with high-intensity physical activity versus a continuous moderate-intensity physical activity bout: A randomised crossover trial. J Sci Med Sport 2018; 21: 1250-1255

[39] Altenburg TM, Rotteveel J, Dunstan DW, Salmon J, Chinapaw MJ. The effect of interrupting prolonged sitting time with short, hourly, moderate-intensity cycling bouts on cardiometabolic risk factors in healthy, young adults. J Appl Physiol (1985) 2013; 115: 1751-1756

[40] Engeroff T, Fuzeki E, Vogt L, Banzer W. Breaking up sedentary time, physical activity and lipoprotein metabolism. J Sci Med Sport 2017; 20: 678-683

[41] Greiwe JS, Holloszy JO, Semenkovich CF. Exercise induces lipoprotein lipase and GLUT-4 protein in muscle independent of adrenergic-receptor signaling. J Appl Physiol (1985) 2000; 89: 176-181

[42] Kim IY, Park S, Trombold JR, Coyle EF. Effects of moderate- and intermittent low-intensity exercise on postprandial lipemia. Med Sci Sports Exerc 2014; 46: 1882-1890

[43] Miyashita M, Burns SF, Stensel DJ. Exercise and postprandial lipemia: Effect of continuous compared with intermittent activity patterns. Am J Clin Nutr 2006; 83: 24-29

[44] Miyashita M, Park JH, Takahashi M, Suzuki K, Stensel D, Nakamura Y. Postprandial lipaemia: Effects of sitting, standing and walking in healthy normolipidaemic humans. Int J Sports Med 2013; 34: 21-27

[45] Peddie MC, Rehrer NJ, Perry TL. Physical activity and postprandial lipidemia: Are energy expenditure and lipoprotein lipase activity the real modulators of the positive effect? Prog Lipid Res 2012; 51: 11-22

[46] Yates T, Edwardson CL, Celis-Morales C, Biddle SJH, Bodicoat D, Davies MJ, Esliger D, Henson J, Kazi A, Khunti K, Sattar N, Sinclair AJ, Rowlands A, Velayudhan L, Zaccardi F, Gill JMR. Metabolic effects of breaking prolonged sitting with standing or light walking in older South Asians and White Europeans: A randomized acute study. J Gerontol A Biol Sci Med Sci 2018, doi:10.1093/gerona/gly252 